Original Article

\title{
Effects of inspiratory muscle training on pulmonary functions and muscle strength in sedentary hemodialysis patients
}

\author{
Heba A. Bahey El-Deen, PhD ${ }^{1,2)}$, Fahad Salam Alanazi, PhD ${ }^{3)}$, \\ Khaled Takey Ahmed, PhD ${ }^{4,5}$ )* \\ 1) Physical Therapy Department and Health Rehabilitation, Faculty of Applied Medical Sciences, \\ Aljouf University, Saudi Arabia \\ 2) Physical Therapy Department for Surgery, Faculty of physical Therapy, Misr University for Science \\ and Technology, Egypt \\ 3) Physical Therapy Department and Health Rehabilitation, Faculty of Applied Medical Sciences, \\ Aljouf University, Saudi Arabia \\ 4) Physical Therapy Department, Faculty of Health Sciences, Beirut Arab University: Beirut, Lebanon \\ 5) Physical Therapy Department for Cardiopulmonary Disorders and Geriatrics, Faculty of Physical \\ Therapy, Misr University for Science and Technology, Egypt
}

\begin{abstract}
Purpose] This study was conducted to evaluate the effect of Inspiratory Muscle Trainer (IMT) on respiratory muscle strength and pulmonary functions. [Subjects and Methods] Fifteen sedentary unemployed patients were recruited from both genders who received regular hemodialysis sessions from at least three months. Those patients received Threshold IMT program for 12 weeks. Pulmonary functions and respiratory muscle strength in form of (PImax) and (PEmax) were measured by electronic spirometry and digital pressure vacuum meter respectively. Additionally oxygen saturation was measured by Finger pulse oximeter. All measurements were performed before and at the end of the treatment program after 12 weeks. [Results] The results of this study revealed significant improvement in $\mathrm{FVC} \%$, FEV1\%, PEF\%, PImax and PEmax after three months of treatment by using inspiratory muscle trainer while no significant difference was recorded regarding to $\mathrm{FEV} 1 / \mathrm{FVC} \%$ ratio and $\mathrm{SpO}_{2}$. [Conclusion] Inspiratory muscle trainer is an effective therapeutic technique to improve respiratory muscle strength and pulmonary functions in patients undergoing hemodialysis.

Key words: Inspiratory muscle trainer, Pulmonary functions, Hemodialysis
\end{abstract}

(This article was submitted Sep. 26, 2017, and was accepted Dec. 15, 2017)

\section{INTRODUCTION}

Renal replacement therapy represents an essential treatment for about 1 million persons who have end stage renal disease $(\mathrm{ESRD})^{3)}$. End stage renal failure is rapidly propagating in both developed and developing countries ${ }^{4)}$.

Multiple systems such as musculoskeletal, cardiovascular and respiratory systems are extremely affected in renal dialysis patients. Moreover, various pulmonary complications are common in hemodialysis patients either from dialysis process or from the disease impact itself ${ }^{5-8)}$. Such complications as accumulation of uremic toxins (urea and creatinine), volume overload from fluid retention and anemia from lack of erythropoietin production. All of which may lead to a reduction in respiratory muscle strength and function ${ }^{9-11)}$. Other reasons for respiratory complications are malnutrition, accompanied by muscular wasting ${ }^{1)}$. Additionally, electrolyte and acid-base imbalances. All of which may affect respiratory muscles as well ${ }^{12)}$.

*Corresponding Author. Khaled Takey Ahmed (E-mail: k.ahmadabdallah@bau.edu.lb)

C2018 The Society of Physical Therapy Science. Published by IPEC Inc.

This is an open-access article distributed under the terms of the Creative Commons Attribution Non-Commercial No Derivatives (by-nc-nd) License. (CC-BY-NC-ND 4.0: https://creativecommons.org/licenses/by-nc-nd/4.0/) 
Physical therapy unlocks a new era by effectively contributing into what is called renal rehabilitation. The current study is attempting to unveil the essential role of physical therapy as an inseparable part of the treatment program for hemodialysis patients. Consequently, strengthening of respiratory muscles by using threshold inspiratory muscle trainer for those patients may enhance the function of the pulmonary system entirely.

The present study was conducted to evaluate the effect of 12 weeks of IMT on respiratory muscle strength and pulmonary functions in hemodialysis patients.

\section{SUBJECTS AND METHODS}

Fifteen patients from both genders ( 9 males and 6 females) with chronic kidney disease were recruited in the study. All patients were unemployed living a sedentary lifestyle. They received regular hemodialysis sessions at least three months previously, at a hemodialysis unit of Al-Kasr Al Aini hospital, at faculty of medicine, Cairo University, Egypt. All of them had vascular access through an arteriovenous fistula. Their ages ranged from 45 to 65 years old. All of them were initially examined by a specialized physician. All patients fully understood the purpose and procedures of the study and so an informed consent was signed by each patient who agreed to participate in the study. All patients received intradialytic inspiratory muscle training for 3 days per week in a total of 12 weeks. A Single-group interventional study design was used to confirm the influence of inspiratory muscle training in haemodialytic patients. This study was carried out according to the principles of the Declaration of Helsinki 1975, revised Hong Kong 1989 and was approved by human research ethics committee of the Faculty of Physical Therapy, Cairo University.

Patients who were clinically stable and had sufficient level of cognition and ability to understand instructions were included in the study. Patients who had the following criteria such as chronic chest, cardiac, neurological disease or a current smoking habit which may interfere with exercise training were excluded from the study. All patients, regardless of their health status were allowed to discontinue exercise training program and withdraw from the study at any time.

Measuring pulmonary function test by an electronic Spirometer (Model-Schiller AG, CH6304) was used to measure forced vital capacity (FVC), forced expiratory volume in one second (FEV1), FVC $\backslash$ FEVI ratio, peak expiratory flow (PEF) based on the total pulmonary capacity. Guidelines of the Pulmonary Function Tests were used with all patients in the study ${ }^{13,14)}$.

Measuring respiratory muscle strength by digital pressure vacuum meter (VACU. MED Ventura, CA, USA) was used to measure PImax through an inspiratory maneuver based on the functional residual capacity and PEmax based on total lung capacity after clipping the nose. Each patient was sitting comfortably in a 90-degrees position. For both measures, three attempts were recorded and the best of them was chosen ${ }^{3,15,16)}$. Measuring peripheral oxygen saturation $\left(\mathrm{SpO}_{2}\right)$ by Finger pulse oximeter (Ana Pulse 100, Ana Wiz Ltd., UK) was positioned on the patient's forefinger tip to measure $\mathrm{SpO}_{2}$.

All measurements were performed at the same day, once before the beginning of the study and another after completion of 12 weeks of inspiratory muscle training program.

Inspiratory muscle training program was conducted by Threshold IMT (HS 730-010 for Respiratory Drug Delivery, Ltd., UK) with a dial selector used to detect the resistance level. The device contains a valve to ensure consistent resistance regardless of the air flow that trains respiratory muscles. Each patient breathes through a separate mouthpiece. The resistance is adjusted at $50 \%$ of maximum inspiratory pressure detected from pressure vacuum meter and is marked on the training device. A single training session consists of five sets, each contains five inspirations with total of twenty five breaths with one minute of recovery between each set. The resistance was adjusted every week to be $50 \%$ of the new maximum inspiratory pressure and if it remained the same, the subject continued to train at the level of the previous week ${ }^{17)}$.

The (SPSS, Version 17) statistical software package was used for statistical analysis. For descriptive statistics, mean and standard deviations were calculated for all variables, and analytical statistics, paired t-test was used to test if there is a significant difference between pre and post means of the measured variables. Level of significance was set at $(p<0.05)$.

\section{RESULTS}

Demographic details of the study sample and summarized baseline measures were shown in Table 1 . The study sample comprised fifteen patients on hemodialysis sessions ( 9 females and 6 males). The mean value and SD of their ages was 50.3 \pm 6.6 years while the mean value and SD of their Body Mass Index (BMI) was 29.8 \pm 3.8 .

Comparing the mean values and standard deviations of pulmonary functions before and after three months of treatment by using inspiratory muscle trainer were shown in Table 2 . Results revealed statistically significant difference $(\mathrm{p}<0.05)$ for $\mathrm{FVC} \%$, and $\mathrm{FEV1 \%}$ where the mean difference was 12.2 and 15.6 respectively with (p-value 0.0001 ), while the mean difference for $\mathrm{PEF} \%$ was 14.1 with (p-value 0.0001). However, there was no statistical significant difference (p>0.05) for (FEV1/ FVC \%) where the mean difference was 7.5 with (p-value 0.18). Additionally, results of the current study revealed significant difference $(\mathrm{p}<0.05)$ as regard to PImax and PEmax where the mean difference was 9.2 and 14 respectively with (p-value 0.002) and (p-value 0.0001) before and after three months of treatment as shown in Table 2. Moreover, results of the present study revealed no statistical significant difference $(\mathrm{p}>0.05)$ for $\mathrm{O}_{2}$ saturation $\left(\mathrm{SpO}_{2}\right)$ as the mean difference was 0.8 with (p-value 0.08 ) before and after three months of treatment as shown in Table 2. 
Table 1. Demographic data of the study group

\begin{tabular}{lc}
\hline \multicolumn{1}{c}{ Variables } & Mean $\pm \mathrm{SD}$ \\
\hline Age $($ years $)$ & $50.3 \pm 6.6$ \\
Height $(\mathrm{cm})$ & $163.1 \pm 6.6$ \\
Weight $(\mathrm{kg})$ & $79.4 \pm 11.0$ \\
BMI $\left(\mathrm{kg} / \mathrm{m}^{2}\right)$ & $29.8 \pm 3.8$ \\
\hline
\end{tabular}

SD: Standard deviation.
Table 2. The mean values, standard deviations and mean difference between pre and post treatment for all measured variables of the study group

\begin{tabular}{lccc}
\hline \multirow{2}{*}{ Variables } & Pre treatment & Post treatment & \multirow{2}{*}{ Mean difference } \\
\cline { 2 - 3 } & Mean $\pm \mathrm{SD}$ & Mean $\pm \mathrm{SD}$ & \\
\hline FVC (\%) & $53.5 \pm 12.3$ & $65.7 \pm 11.1^{*}$ & 12.2 \\
FEV1 (\%) & $52.9 \pm 15.1$ & $68.4 \pm 10.4^{*}$ & 15.6 \\
FEV1/FVC (\%) & $103.1 \pm 18.6$ & $110.6 \pm 11.9$ & 7.5 \\
PEF (\%) & $39.9 \pm 15.6$ & $53.9 \pm 16.1^{*}$ & 14.05 \\
PImax $\left(\mathrm{cmH}_{2} \mathrm{O}\right)$ & $77.3 \pm 26.7$ & $86.5 \pm 20.3^{*}$ & 9.2 \\
$\mathrm{PEmax}_{\left(\mathrm{cmH}_{2} \mathrm{O}\right)}$ & $45.9 \pm 19.4$ & $59.9 \pm 14.9^{*}$ & 14 \\
$\mathrm{SpO}_{2}$ & $96.6 \pm 1.8$ & $97.40 \pm 1.05$ & 0.8 \\
\hline
\end{tabular}

*Significant $(\mathrm{p}<0.05)$ difference between pre and post 3 months. FVC $(\%)$ : Forced Vital Capacity; (FEV1): Forced Expiratory Volume in one second; (FVC $\backslash$ FEVI \% ratio); (PEF\%): Peak Expiratory Flow; PImax $\left(\mathrm{cmH}_{2} \mathrm{O}\right)$ : Maximum Inspiratory Pressure; PEmax $\left(\mathrm{cmH}_{2} \mathrm{O}\right)$ : Maximum Expiratory Pressure; SD: Standard deviation.

\section{DISCUSSION}

Many studies found a reduction in baseline inspiratory and expiratory muscle strength and pulmonary functions in patients with ESRD when compared to healthy subjects ${ }^{17-19}$.

Moreover, Kosmadakis et al. ${ }^{20)}$ assured that resistive exercises training program in patients with chronic kidney disease (CKD) may reduce skeletal muscle atrophy. Their findings coincided with our results, which revealed that the use of IMT device as a resistive training program for respiratory muscles reduces its atrophy and increases its strength. Supposedly, this improvement would enhance pulmonary functions.

Rahgoshai et al. ${ }^{2)}$ concluded that there was acute significant improvement in FVC in patients of hemodialysis after dialysis sessions while non-significant for VC, FEV1 and FEV1/FVC ratio. They assured that the improvements in pulmonary functions are temporary and incomplete. Our results verified the essentiality of another physical intervention to improve all pulmonary functions as well as respiratory muscle strength.

Results of the current study showed significant improvement in $\mathrm{FVC} \%$, FEV1\%, and PEF\% while no significant improvement for FEV1/FVC ratio can be achieved with application of IMT during hemodialysis sessions for 12 weeks. This contradicts the data presented by Da Silva et al. ${ }^{21)}$ who showed no statistically significant difference in variables of pulmonary functions concerning FVC, FEV1, FEV1/FVC ratio and both (PImax) and (PEmax) by comparing values before and after eight weeks of IMT. This contradiction may be due to the difference in the total duration of treatment program.

The current study used pressure vacuum meter to test respiratory muscle strength through measuring both PImax and PEmax that was in accordance with other studies ${ }^{3,22}$ which reported that measuring PImax and PEmax represent the most accurate test for the detection of respiratory muscle strength. Moreover, Moreno et al. ${ }^{23}$ clarified that body position affects the measures of respiratory pressure in both normal and CKD patients. Hence, during the maneuver with pressure vacuum meter, the position of all individuals of the present study was unified at 90 degrees position in all measurements either pulmonary functions or respiratory pressures. Results of the current study showed significant improvement in PImax, and PE max, which coincided with Pellizzaro et al. ${ }^{17)}$ who applied IMT program for 10 weeks and found significant improvement in both PImax and PEmax.

Ezzat and Mohab ${ }^{24}$ stated that baseline $\mathrm{O}_{2}$ saturation decreased in CKD patients in comparison to healthy subjects while in our patients the baseline $\mathrm{O}_{2}$ saturation was within normal values with no significant difference between their baseline readings and after 12 weeks of treatment. This result comes in agreement with the results of Da Silva et al. ${ }^{21)}$ who reported no significant difference between baseline reading of $\mathrm{O}_{2}$ saturation and after treatment by IMT for eight weeks.

Many studies ${ }^{25-27)}$ confirmed that intradialytic exercise therapy, regardless of its type, is more engaging and encouraging to HD patients. Therefore, our study preferred the application of intradialytic inspiratory training program to guarantee the completion of training session under direct supervision. It was also observed that our patients were so motivated to perform such activities during dialysis sessions. According to Sousa et al. ${ }^{28)}$ patients of our study performed the IMT protocol during the first 30 minutes of hemodialysis to avoid any cardiac alterations during the treatment.

It was concluded that inspiratory muscle trainer is an effective and adjunct therapeutic technique to improve respiratory muscle strength and pulmonary functions in patients undergoing hemodialysis.

\section{Conflict of interest}

The authors report no conflicts of interest. 


\section{REFERENCES}

1) Yoon SH, Choi NW, Yun SR: Pulmonary dysfunction is possibly a marker of malnutrition and inflammation but not mortality in patients with end-stage renal disease. Nephron Clin Pract, 2009, 111: c1-c6. [Medline] [CrossRef]

2) Rahgoshai R, Rahgoshai R, Khosraviani A, et al.: Acute effects of hemodialysis on pulmonary function in patients with end-stage renal disease. Iran J Kidney Dis, 2010, 4: 214-217. [Medline]

3) dos Reis Santos I, Danaga AR, de Carvalho Aguiar I, et al.: Cardiovascular risk and mortality in end-stage renal disease patients undergoing dialysis: sleep study, pulmonary function, respiratory mechanics, upper airway collapsibility, autonomic nervous activity, depression, anxiety, stress and quality of life: a prospective, double blind, randomized controlled clinical trial. BMC Nephrol, 2013, 14: 215. [Medline] [CrossRef]

4) Soliman AR, Fathy A, Roshd D: The growing burden of end-stage renal disease in Egypt. Ren Fail, 2012, 34: 425-428. [Medline] [CrossRef]

5) Reboredo MM, Henrique DM, Bastos MG, et al.: Physical exercise in dialysis patient. Rev Bras Med Esporte, 2007, 13: 427-430. [CrossRef]

6) Coelho DM, Castro AM, Tavares HA, et al.: Effects of a physical exercising program on conditioning of hemodialysis patients. J Bras Nefrol, 2006, 18: 121-127.

7) Schardong TJ, Lukrafka JL: Garcia VD. Assess Pulm Funct Qual Life Patients Mainten Hemodial J Bras Nefrol, 2008, 30: 40-47.

8) Faria RS, Silva VS, Reboredo MM, et al.: Evaluation of the respiratory function, physical capacity and quality of life in patients with pre-dialysis chronic kidney disease. J Bras Nefrol, 2008, 30: 264-271.

9) Kovelis D, Pitta F, Probst VS, et al.: Pulmonary function and respiratory muscle strength in chronic renal failure patients on hemodialysis. J Bras Pneumol, 2008, 34: 907-912. [Medline] [CrossRef]

10) Jatobá JP, Amaro WF, Andrade AP, et al.: Assessment of the pulmonary function, respiratory muscular strength and six-minute walk test in chronic kidney disease patients on hemodialysis. J Bras Nefrol, 2008, 30: 280-287.

11) Pappa M, Dounousi E, Duni A, et al.: Less known pathophysiological mechanisms of anemia in patients with diabetic nephropathy. Int Urol Nephrol, 2015, 47 : 1365-1372. [Medline] [CrossRef]

12) Senatore M, Buemi M, Di Somma A, et al.: [Respiratory function abnormalities in uremic patients]. G Ital Nefrol, 2004, 21: 29-33 (In Italian). [Medline]

13) Souza RB: Maximum static respiratory prssure. J Bras Pneumol, 2002, 28: S155-S165.

14) Pereira CA, Sato T, Rodrigues SC: New reference values for forced spirometry in white adults in Brazil. J Bras Pneumol, 2007, 33: 397-406. [Medline] [CrossRef]

15) Teixeira CG, Duarte MC, Prado CM, et al.: Impact of chronic kidney disease on quality of life, lung function, and functional capacity. J Pediatr (Rio J), 2014, 90: 580-586. [Medline] [CrossRef]

16) Casali CC, Pereira AP, Martinez JA, et al.: Effects of inspiratory muscle training on muscular and pulmonary function after bariatric surgery in obese patients. Obes Surg, 2011, 21: 1389-1394. [Medline] [CrossRef]

17) Pellizzaro CO, Thomé FS, Veronese FV: Effect of peripheral and respiratory muscle training on the functional capacity of hemodialysis patients. Ren Fail, 2013, 35: 189-197. [Medline] [CrossRef]

18) Weiner P, Zidan F, Zonder HB: Hemodialysis treatment may improve inspiratory muscle strength and endurance. Isr J Med Sci, 1997, 33: 134-138. [Medline]

19) Bohannon RW, Hull D, Palmeri D: Muscle strength impairments and gait performance deficits in kidney transplantation candidates. Am J Kidney Dis, 1994, 24: 480-485. [Medline] [CrossRef]

20) Kosmadakis GC, Bevington A, Smith AC, et al.: Physical exercise in patients with severe kidney disease. Nephron Clin Pract, 2010, 115: c7-c16. [Medline] [CrossRef]

21) Da Silva VG, Amaral C, Monteiro MB, et al.: Effects of inspiratory muscle training in hemodialysis 21 patients. J Bras Nefrol, 2011, 33: 45-51.

22) Magnani KL, Cataneo AJ: Respiratory muscle strength in obese individuals and influence of upper-body fat distribution. Sao Paulo Med J, 2007, 125: 215-219. [Medline] [CrossRef]

23) Moreno MA, Silva E, Gonçalves MO: The effect of proprioceptive neuromuscular facilitation techniques—Kabat Method—on maximum respiratory pressure. Physiother Mov, 2005, 18: 53-61.

24) Ezzat H, Mohab A: Prevalence of sleep disorders among ESRD patients. Ren Fail, 2015, 37: 1013-1019. [Medline] [CrossRef]

25) Brenner I: Exercise performance by hemodialysis patients: a review of the literature. Phys Sportsmed, 2009, 37: 84-96. [Medline] [CrossRef]

26) Henrique DM, Reboredo MM, Chaoubah A, et al.: [Aerobic exercise improves physical capacity in patients under chronic hemodialysis]. Arq Bras Cardiol, 2010, 94: 823-828 (In Portuguese). [Medline] [CrossRef]

27) Böhm J, Monteiro MB, Thomé FS: [Effects of aerobic exercise during haemodialysis in patients with chronic renal disease: a literature review]. J Bras Nefrol, 2012, 34: 189-194 (In Portuguese). [Medline]

28) Sousa JF, Ribeiro JC, Correia C, et al.: Effects of aerobic exercise program on physical activity levels in hemodialysis patients. Motricidade, 2014, 10: $72-80$. 